\title{
¿Un momento maquiaveliano en Arendt? Republicanismo y revolución *
}

\author{
A Machiavellian moment in Arendt? Republicanism and revolution
}

\author{
Sebastián Torres \\ sebatorres7@hotmail.com \\ (Universidad Nacional de Córdoba, Córdoba, Argentina)
}

\begin{abstract}
Resumen: Nos proponemos analizar la lectura que Arendt realiza de Maquiavelo entre fines de los 1950 y mediados de los 1960, bajo la hipótesis de que en sus continuidades y desplazamientos pueden encontrarse algunas claves para comprender el complejo y problemático vínculo, que emerge más allá de ciertas similitudes estructurales, entre la autora y la recuperación de la llamada "tradición republicana". Al final, proponemos una aproximación a lo que podría reconocerse como un "momento maquiaveliano" en el interior de la permanencia en Arendt del interrogante por la fundación de la institución política.
\end{abstract}

Palabras-clave: Arendt; Maquiavelo; republicanismo; revolución.

\begin{abstract}
The aim of this paper is to analize Arendt's reading of Machiavelli between the late fifties and the mid-sixties, according to the hypothesis that in its continuities and shifts some keys can be found to understand the complex and problematic relationship, which emerges beyond certain structural similarities, between Arendt and the recovery of the so called "republican tradition". We will propose at the end that a "machiavellian moment" could be recognized as an episode in Arendt's permanent concern for the foundations of the political institution.
\end{abstract}

Keywords: $\quad$ Arendt; Machiavelli; republicanism; revolution.

\section{Arendt, Maquiavelo y la cuestión republicana}

Toda lectura de Hannah Arendt que pretenda abordar su obra como parte de la reciente recuperación del republicanismo supone una operación de reconstrucción retrospectiva. Si adoptamos como principio de lectura la obra fundacional del neorepublicanismo The machiavellian moment de J.G.A. Pocock, publicada en 1975 (año

\footnotetext{
* Este trabajo es el resultado de un conjunto de hipótesis de lectura presentadas en el Seminario “Arendt y la tradición filosófico-política: entre La condición humana y Sobre la Revolución", en marzo de 2013, luego expuestas en las IV Jornadas Internacionales Hannah Arendt: Sobre a Revolução 50 anos, en noviembre del mismo año, actividades organizadas por el Instituto de Filosofía y Ciencias Humanas de la Universidad Estadual de Campinas. Quisiera agradecer a Julia Smola, con quien dictamos el seminario, por su valiosa orientación en la lectura de Arendt y especialmente a Yara Frateschi por la invitación a discutir estos temas y por una hospitalidad que durante años ha hecho de la conversación un espacio de encuentro fundamental para nuestras universidades.
} 
de la muerte de Arendt), es en el período que va de fines de los 1950 a mediados de los 1960 donde la obra de Arendt se aproxima a ciertos núcleos de esta tradición. Pasará más de una década para que el neo-republicanismo adquiera una identidad propia, período coincidente con el momento del redescubrimiento más amplio la obra de Arendt - cuya lectura por supuesto tuvo un alcance mucho mayor a esta teoría -, quedando muchas veces solapada y otras ligada directamente a sus núcleos programáticos.

En el primer capítulo del significativo libro Vida del espíritu y tiempo de la polis, Simona Forti reseña una serie de vías de interpretación de la obra de Arendt, entre las que menciona la llamada "rehabilitación de la filosofía práctica" alemana, que comienza en los años 1960 y, por otra parte, la discusión en torno al republicanismo, impulsada por la obra de J.G.A. Pocock (cf. Forti, 2001, pp.17-52). Forti no propone de manera directa alguna conexión entre el neo-republicanismo anglosajón y el neo-aristotelismo alemán que permita una lectura más allá de la interrogación sobre las diferentes recepciones de la obra arendtiana. Sin embargo, si volvemos al contexto precedente de preocupaciones próximas a Arendt encontramos un vínculo pocas veces señalado: la propia génesis de la obra de Pocock se reconoce deudora de las investigaciones de Hans Baron y Felix Gilbert, historiadores de las ideas políticas y reconocidos precursores de los estudios sobre el humanismo cívico republicano, ambos alemanes exiliados en EEUU'. Así, la matriz aristotélica presente en la Rehabilitierung alemana (cf. Volpi, 1999, pp.315-6; 1988, pp.111-35) y el republicanismo oceánico podrían tener un origen común - o, por lo menos, una serie de motivaciones comunes - y ser la clave para pensar el singular republicanismo de Arendt. Pero más allá de estas confluencias de principios de siglo XX y de las vías teóricas autónomas surgidas a partir de los años 1960, una diferencia fundamental separa este recomienzo de un republicanismo contemporáneo: el lugar que ocupa Maquiavelo, central para J.G.A. Pocock y Quentin Skinner, frente al dominante antimaquiavelismo del neo-aristotelismo alemán (una oposición a Maquiavelo que habilitará la confluencia entre el neo-aristotelismo y el neo-kantismo)2.

Pensar a Arendt en esta amplia constelación intelectual nos muestra el complejo mapa en el que se inscribiría su relación con el republicanismo ${ }^{3}$, cuya dimensión no se agota en las operaciones retrospectivas para incluirla en esta tradición según los lineamientos contemporáneos del debate, que poseen una valencia propia. Sería

1 Baron, 1928 y principalmente Baron, 1955. Arendt poseía un ejemplar de Gilbert, 1965.

2 La reconstrucción de un "republicanismo" alemán, sus diversas fuentes y variantes, sería objeto de una investigación aparte. En la mayoría de los casos la relación con Maquiavelo es problemática o ambigua, como puede verse en las mismas lecturas de Baron y Gilbert, en Sternberger, 1992 (de 1980) y en Riedel, 1976 (de 1975), así como en Habermas, 1987 (de 1963).

3 Una constelación a la que podrían sumarse los desarrollos propios de la tradición norteamericana, sobre todo en el campo de la historia Cf. Souroujon, 2011. 
tentador pensar, según lo que hemos dicho y por motivos claramente reconocibles, dos momentos de esta relación: el primero, ligado a La condición humana y más próximo al neo-aristotelismo alemán, el segundo, ligado a Sobre la revolución, más próximo al neo-republicanismo atlántico. Pero un elemento, que será motivo de nuestro desarrollo, parece impedirlo: el lugar que ocupa en Arendt la lectura de Maquiavelo. Volviendo a Pocock, la singular “coincidencia de intereses" con Arendt, donde el republicanismo sería un arco subterráneo que enlaza el aristotelismo con el pensamiento político de la revolución americana, encuentra, sin embargo, divergencias mutuas. Por una parte, la significativa ausencia del humanismo cívico renacentista en la obra de Arendt, sobre todo en La condición humana ${ }^{4}$, atendiendo, por ejemplo, a la polémica entre vita activa y contemplativa, que resulta central para ambas reconstrucciones históricas. Por otra parte, la llamativa ausencia de una justa recepción de Arendt por parte de Pocock, que por supuesto conocía su obra ${ }^{5}$.

Esta introductoria reconstrucción intelectual tiene por objeto mostrar el complejo pero vinculado mapa que compone el interrogante por el republicanismo de Arendt, pero también la dificultad de resolverlo sólo y exclusivamente a partir de una interpretación en clave aristotélica o reuniendo ese conjunto más amplio de afinidades con la tradición republicana que cualquier lector atento podría identificar. Nuestra hipótesis de lectura es que Maquiavelo resulta un fundamental índice para comprender, por una parte, las divergencias y proximidades de Arendt con el neoaristotelismo y el neo-republicanismo y, por otra parte, es una clave para comenzar a delinear un singular republicanismo arendtiano.

En los comentadores e intérpretes de Arendt son constantes las referencias a la presencia de Maquiavelo en su obra, generalmente asociado a los nombres de Montesquieu y Tocqueville. En general, estas referencias tienen por objetivo explicar la categoría arendtiana de "escritor político", que difiere tanto del filósofo como del cientista. El nombre de Maquiavelo aparecerá fragmentariamente a lo largo de toda su obra: las referencias principales se encuentran en La condición humana (1958), en el ensayo que integra la edición de Entre pasado y futuro titulado ¿Qué es la autoridad? (1961), en Sobre la revolución (1963) y en algunos de sus cursos, todavía inéditos; las lectures "History of Political Theory" de 1955, dictadas en la Universidad de California (donde realiza un recorrido de Machiavelli a Marx); el seminario "Machiavelli" de 1961, dictado en la Universidad de Wesleyan; y el curso "From Machiavelli to Marx" de 1965, dictado en la Universidad de Cornell (que

\footnotetext{
4 Recordemos que el título de los cursos que da origen a La condición humana era el de "Vita activa", que se mantendrá como título en la edición alemana (Vita activa oder vom tätigen Leben. Stuttgart: Kohlhammer, 1960). En particular, es en la obra de Hans Baron donde encontramos un extenso desarrollo de la polémica entre vita activa y vita contemplativa como principio constitutivo de la reconstrucción del Bürgerhumanismus, posteriormente traducido al inglés como Civic Humanism.

5 Arendt es mencionada dos veces al final de la obra, en breves pasajes poco relevantes, una vez refiriéndose a Sobre la revolución y otra a La condición humana. Cf. Pocock, 2002, pp.618 y 654-655.
} 
replica, con modificaciones, las lectures dictadas diez años antes). Sin embargo, los estudios sobre la lectura que Arendt propone de Maquiavelo son escasos, situación que podría justificarse por los aislados y reducidos momentos en donde es abordado, no así si atendemos a la insistente mención de su nombre entre aquellos pensadores de la tradición que resultarían fundamentales para su obra.

Este trabajo no pretende llenar ese vacío, no nos proponemos un estudio sobre la interpretación que Arendt realiza de Maquiavelo, sobre sus fuentes, y sus coincidencias y divergencias con las interpretaciones de sus contemporáneos. Como afirmamos antes, lo que nos interesa es explorar de qué manera las menciones de Maquiavelo constituyen indicios que permiten echar luz sobre la hipótesis de un republicanismo arendtiano. Para ello, vamos a seguir tres pasos: en primer lugar, mostrar a Maquiavelo como interdicción sobre el supuesto neo-aristotelismo presente en La condición humana; en segundo lugar, mostrar de qué manera Maquiavelo es un punto polémico en la aparente afinidad que podría encontrarse en Sobre la revolución con el "republicanismo atlántico"; y, finalmente, esbozar algunos elementos que se desprender de su lectura para ver en Maquiavelo un punto de inflexión entre la idea de fundación clásica y la moderna, que estará en el centro de sus reflexiones sobre la revolución.

\section{La interdicción al aristotelismo}

Maquiavelo aparece por primera vez en La condición humana, en el apartado dedicado a la distinción entre "La esfera pública y la privada". Inmediatamente después de una breve genealogía del pensamiento medieval -de la que concluye que no debería resultarnos sorprendente que en este período se desconociera la distinción entre la esfera doméstica y la dura exposición de la polis a la que se veía sometido el ciudadano y, por tanto, al consiguiente desconocimiento de la virtud del valor -, nos dice:

Lo que continua siendo sorprendente es que el único teórico político postclásico que, en su extraordinario esfuerzo por restaurar la vieja dignidad de la política, captó dicha separación y comprendió algo del valor necesario para salvar esa distancia fue Maquiavelo, quien lo describió en el ascenso «del condotiero desde su humilde condición al elevado rango», de la esfera privada a la principesca, es decir, de las circunstancias comunes a todos los hombres a la resplandeciente gloria de las acciones (Arendt, 1998, p.47, la cursiva es nuestra) ${ }^{6}$.

6 El pasaje continua: "Quien entra en la esfera política debía estar preparado para arriesgar su vida, y el excesivo afecto hacia la propia existencia impedía la libertad, era una clara señal de servidumbre. Por lo tanto, el valor se convirtió en la virtud política por excelencia (...) La «buena vida», como Aristóteles calificaba a la del ciudadano, no era simplemente mejor (...) sino de una calidad diferente por completo. Era «buena» en el grado en que (...) ya no estaba ligada al proceso biológico vital” (Arendt, 1998, p.47). 
El pasaje conserva cierta ambigüedad: ¿por qué sorprende que el único teórico postclásico que captó esta separación haya sido Maquiavelo? ¿Acaso Arendt desconocía la tradición del humanismo cívico? Maquiavelo aparece como una isla, aunque sólo comprendió algo del valor necesario para salvar esa distancia: no nos dice qué es lo que le faltó, pero sí nos indica unas líneas más adelante que "En la raíz de la conciencia política griega hallamos una inigualada claridad y articulación en el trazado de esta distinción" (Arendt, 1998, p.47). Nada encontramos aquí de la polémica entre el Maquiavelo republicano de los Discursos a la primera década de Tito Livio y el Maquiavelo teórico de las nuevas monarquías de El Príncipe: es la figura del condotiero de El Príncipe y no a las virtudes cívicas del cittadino de los Discursos la que, en su soledad, traza un continuum con el valor de la "buena vida" aristotélica, desligada del "proceso biológico vital". Solitario en un particular clasicismo, Arendt no releva aquí su singular excepcionalidad vinculada con otro concepto de necessità, que nada tiene que ver con la diferencia entre la necesidad natural del oikos frente a la libertad de la polis y que resultará central para la idea maquiaveliana de virtù (uno de los motivos de la contienda entre aristotelismo y maquiavelismo).

Maquiavelo resulta un aislado embate postclásico al pensamiento político medieval, sobre todo por lo que expresamente será el núcleo de su confrontación: la crítica de la relación entre moral religiosa y política:

La bondad, por lo tanto, como consistente forma de vida, no es sólo imposible dentro de los confines de la esfera pública, sino que incuso es destructiva. Quizás nadie ha comprendido tan agudamente como Maquiavelo esta ruinosa cualidad de ser bueno, quien, en un famoso párrafo, se atrevió a enseñar a los hombres «cómo no ser bueno». Resulta innecesario añadir que no dijo ni quiso decir que a los hombres se les debe enseñar a ser malos; el acto criminar, si bien por otras razones, también ha de huir de ser visto y oído por los demás. El criterio de Maquiavelo para la acción política era la gloria, el mismo que en la antigüedad clásica, y la maldad no puede brillar más gloriosa que la bondad (Arendt, 1998, pp.82-3, la cursiva es nuestra).

Arendt vuelve a aproximar a Maquiavelo con el pensamiento clásico, pero el pasaje va más allá de la conocida distinción aristotélica entre el buen hombre y el buen ciudadano. La afirmación del carácter destructivo del bien en la esfera pública, y más en general de la sobredeterminación moral de la política, es una idea que nadie comprendió tan agudamente como Maquiavelo. No se trata sólo del redescubrimiento de la gloria pública, sino de una nueva configuración de lo político que impugna lo común como bien moral y a la ética como principio normativo que orienta la praxis. Es a partir de esta comprensión, ligada a la crítica de la corrupción producida por la religión cristiana - que "enseñaba al pueblo a ser bueno y no a «resistir el mal», con el resultado de que los "perversos gobernantes hacen todo el mal que les place»", paráfrasis que toma de los Discursos - donde la relación entre ser y aparecer, próximo 
aunque diferente a su configuración clásica ${ }^{7}$, establece una nueva relación entre el bien y política ${ }^{8}$. La refundación de lo público, después de siglos de cristianismo, demandará una distinción con lo privado que excede la claridad aristotélica.

La condición humana no es una historia de la filosofía política, enfatiza la proximidad de Maquiavelo con el mundo clásico y con la polis aristotélica, dejando traslucir de una manera menos explícita sus fundamentales diferencias. Pero una divergencia, que claramente Arendt no ignora (como veremos, ya considerada en su curso de 1955), será silenciada: esa otra "necesidad" que emerge con Maquiavelo y que no podría ser fácilmente ingresada en el esquema "labor, trabajo y acción" que domina una parte central de esta obra, si es leída aristotélicamente. La necesidad maquiaveliana refiere a la necesidad de una nueva fundación de lo público-político que ni se reduce ni se resuelve en la distinción clásica entre necesidad natural y libertad política. En La condición humana, la tensión subterránea entre Maquiavelo y el aristotelismo en relación a la fundamental cuestión de la posibilidad de "lo nuevo" permanecerá oculta tras esa dimensión de la acción pensada a partir del concepto de natalidad, que no es aristotélico ni maquiaveliano. Sin embargo, como veremos, su re-emergencia encontrará un concepto propiamente moderno - y maquiaveliano -: la revolución.

Esta primera aparición de Maquiavelo se distancia parcialmente del neomaquiavelismo republicano de Pocock, pero más clara y radicalmente se opone al antimaquiavelismo del neo-aristotelismo alemán; la idea de virtù política así como la escisión entre ética y política será uno de los problemas modernos que la "rehabilitación de la filosofía práctica" intentará superar. Si, como sostiene Arendt, La condición humana propone ir más allá de la "inversión del platonismo" , es claro entonces que el aristotelismo no puede ser interpretado como una inversión política del platonismo, aunque muchas contraposiciones conceptuales corran el riesgo de sugerir este movimiento. Es por este mismo motivo que el aristotelismo no contiene

7 Sobre este punto, ligado también a la relación entre política y necesidad vital, volverá en los apuntes de ¿Qué es la política? : "la política comenzaba donde acababa la preocupación por la vida. De ahí la virtud cardinal: la valentía. Aquiles y Maquiavelo. Además, históricamente ambos prejuicios van juntos. (...) "La posición socrática: el único filosofar, que tiene lugar públicamente. (...) Sócrates: sé como quisieras parecer, parte de lo público, de su apariencia y brillo. Maquiavelo: parece lo que quisieras ser: parte del ser (ante Dios pero sin Dios: vanidad. Pues nadie puede «ser» sin alguien que mire. Esta es la mundanidad del hombre)" (Arendt, 1997, pp.144-145). Este reenvío al mundo clásico vuelve a aparecer en Arendt, 2003a, p.107.

8 Tema que volverá a aparecer en los textos "Algunas cuestiones de filosofía moral" (1965-1966) y "Responsabilidad colectiva" (1968), editados en Arendt, 2007.

9 "Mi argumento es sencillamente que el enorme peso de la contemplación en la jerarquía tradicional ha borrado las distinciones y articulaciones dentro de la vita activa y que, a pesar de las apariencias, esta condición no ha sufrido cambio esencial por la moderna ruptura con la tradición y la inversión final de su orden jerárquico en Marx y Nietzsche. En la misma naturaleza de la famosa «apuesta al revés» de los sistemas filosóficos o de los actualmente aceptados, esto es, en la naturaleza de la propia operación, radica que el marco conceptual se deje más o menos intacto" (Arendt, 1998, p.29). 
las respuestas a lo que Maquiavelo verá que se encuentra agotado en esta tradición, incluyendo aquel mundo clásico recuperado por el humanismo cívico. Por otra parte, la renuencia de Arendt hacia el procedimiento filosófico de la inversión nos indica también los propios límites de la inversión de lo social sobre lo político como clave de decodificación de la cuestión política moderna, figura en la que Maquiavelo no encaja, no por lo que parece conservar de los clásicos, sino en su propia novedad, que muestra los límites del aristotelismo pesar la modernidad.

\section{El umbral moderno}

La segunda mención a Maquiavelo aparece en dos escritos próximos en varios de sus motivos: en el ensayo ¿Qué es la autoridad? y en Sobre la revolución. Como podremos ver, a diferencia de La condición humana, aquí Maquiavelo es claramente ubicado en el umbral de la época moderna. La diferencia es de perspectiva: su lectura no se modifica sino a partir del ingreso de otra dimensión de su pensamiento. Ubicado en el umbral, la primera obra lo leería desde el lente clásico de la virtud política; ahora será leído desde el lente moderno de la fundación. Maquiavelo no se encuentra en el centro de ¿Qué es la autoridad?, aparece en el apartado final, en una conclusión de rápidos movimientos donde la histórica relación entre autoridad y fundación se ve confrontada a la novedad de la revolución. Maquiavelo es de nuevo reconocido en un privilegiado lugar, propiamente moderno:

hay un pensador político en cuyo trabajo el concepto de fundación es central, si no supremo. Los acontecimientos son las revoluciones de la época moderna y el pensador es Maquiavelo, que se situó en el umbral de esa época y, aunque jamás uso esa palabra, fue el primero en concebir una revolución (Arendt, 2003, p.148).

En las líneas que siguen, con matices aclaratorios, Arendt reitera el mismo análisis realizado en La condición humana sobre el tema de la bondad y la crítica maquiaveliana a la religión (nuevamente a distancia del Medioevo, que en el apartado anterior expuso a partir del vínculo entre la autoridad religiosa y el poder secular moderno). Manteniendo prácticamente intacta la interpretación que había realizado, ahora resalta la grandeza de Maquiavelo ya no en su intento de restauración de la Antigüedad a través de la virtud y la gloria - motivo que sin dudas no perderá relevancia -, sino en la inscripción de la novedad como cuestión política:

[Maquiavelo] no podía sólo restaurar o recurrir a una articulada tradición conceptual sino que él mismo tuvo que articular esas experiencias que los romanos no habían articulado [y] creyó que podía ser posible repetir la experiencia romana [de la fundación] a través de la fundación de una Italia unificada (Arendt, 2003, p.148).

Su interpretación iluminada por el mundo clásico no desaparece: ahora es la experiencia romana la que ofrecerá el hilo conductor de este ensayo, pero la 
aparición de Maquiavelo hace explícita la idea de que ese pasado ya no puede ser ni imitado ni restituido ${ }^{10}$. Las experiencias del pasado sólo cobran sentido a partir de las experiencias del presente, que demandan algo radicalmente nuevo. Instalada la cuestión, Arendt dirá que Maquiavelo nombra la matriz de esa nueva fundación con el término lo stato. Sin embargo, indica que lo más notable no es que, por su experiencia del nacimiento de las naciones modernas, pensara en la necesidad de una nueva entidad política, sino el común lenguaje que hablará con Robespierre, quien repetirá "palabra por palabra los juicios famosos de Maquiavelo sobre la necesidad de la violencia para hallar nuevas entidades políticas y para reformar las corruptas" (Arendt, 2003, p.150).

Como había sucedido en La condición humana, en ¿Qué es la autoridad? también la tradición romana encuentra su interdicción maquiaveliana: la clara asunción de la perspectiva moderna conducirá a la trilogía soberanía-revolución-violencia, siendo este último término el que resultará su signo más propio. La relación entre bien y política, y por extensión la cuestión moderna del mal, ya no podrá provenir de la impugnación frente a la inmoralidad maquiaveliana propia del jesuitismo, la contrarreforma y la ilustración, sino a partir de la relación entre violencia y fundación. Aunque en un pasaje adscribe a la influyente interpretación de Meinecke, colocando a Maquiavelo en el origen de las teorías de la razón de estado, no es esa necesidad conservadora presente en la idea de estado-fuerza la marca de su modernidad, sino la nueva necesidad creadora que asume la violencia como parte constitutiva de la fundación, más próxima pero no idéntica a la crítica post-totalitaria de Cassirer ${ }^{11}$.

Desde Los orígenes del totalitarismo, la cuestión de la violencia atraviesa toda la obra de Arendt, y en ninguno de sus desarrollos construye un cuadro general del problema que contenga todas las perspectivas presentes en su obra (incluso considerando su fundamental ensayo Sobre la violencia). Naturaleza, razón y técnica son las mediaciones a partir de las cuales se han dado históricamente las diferentes formas de relación entre violencia y política, sin embargo, aunque presentes en su obra, no encoraremos en Arendt una explicación que se reduzca a esta filosofía (negativa) de la historia. En particular, reconstruir las referencias de Arendt al decurso del pensamiento alemán - en donde también se trazan las vías del maquiavelismo y el antimaquiavelismo - requeriría un capítulo aparte, cuyo centro es sin duda la

$10 \mathrm{Al}$ respecto, aquí también es relevante la proximidad y la distancia que presenta con el republicanismo neo-romano de Skinner. En particular cfr. Skinner, 2004.

11 Cf. Meinecke, 1959 (de 1924) y Cassirer, 1993 (de 1946). Cabe señalar, sin embargo, que esta aproximación a la interpretación crítica alemana se distancia de la denuncia por la escisión entre ética y política que se expresará en la relación moderna entre mal y poder, como fue planteado por el influyente trabajo de Ritter, 1940 (generalmente citado en la más difundida edición ampliada Die Dämonie der Match de 1948). En español puede verse también Ritter, 1976 (de 1948). Así como también, la ausencia de un vínculo histórico entre maquiavelismo y totalitarismo, que explicaría la ausencia de Maquiavelo en Los orígenes del totalitarismo (a diferencia de los nombres de Montesquieu y Tocqueville, ya presentes en esa obra). Cf. Barbuto, 2005. 
dialéctica hegeliana entre historia y violencia, así como su deriva en el historicismo, el positivismo y el marxismo, es decir, en las filosofías de la historia; corriente alemana frente a la cual la resistencia ilustrada de Cassirer al leer la génesis del Estado moderno en términos de un péndulo entre civilización y barbarie, entre razón y mito, ya fue directamente cuestionada en Los orígenes del totalitarismo. Pero lo cierto es que este vínculo entre Maquiavelo y Robespierre no se encuentra en la raíz de la deriva de cierto maquiavelismo alemán, explícitamente anti-jacobino, como tampoco vuelve a parecer en Sobre la violencia. Lo que, a nuestros fines, muestra la complejidad de la cuestión de la violencia cuando emerge junto a la cuestión de las revoluciones modernas. Sin embargo, no deja de ser válido un interrógate que suscitan las referencias presentes en ¿Qué es la autoridad?: si la proximidad con ciertas tesis del antimaquiavelismo alemán cancelan un republicanismo que tenga un pasaje por Maquiavelo, más allá de la novedosa remisión a la experiencia romana. Aquí Maquiavelo queda suspendido en la pregunta que cierra el ensayo: cómo pensar la fundación moderna a la luz de la revolución. Y la vía que se ahora se abre es atlántica, la de un acontecimiento, sugerido, apenas desplegado a partir de elementos contextuales que sufrirán posteriores modificaciones en una obra central: la experiencia de la revolución norteamericana.

\section{Maquiavelo en la revolución}

No esperamos responder con este breve análisis al conjunto de problemas que se abren en ¿Qué es la autoridad?, nos limitamos a mostrar un punto de inflexión que será determinante para la más sistemática y extensa lectura de Maquiavelo en Sobre la revolución, donde, sin embargo, su lectura parece reforzar la impresión de una coherente continuidad. Recogiendo los mismos motivos de La condición humana y de ¿Qué es la autoridad?, podríamos asumir este análisis - el más extenso y argumentado -, como una lectura de conjunto, reuniendo y resolviendo las tensiones de las dos perspectivas anteriores. Pero, como en cada análisis, Arendt produce una serie de desplazamientos casi imperceptibles que obedecen a una nueva perspectiva: la experiencia de la única "revolución exitosa". En Sobre la revolución todos los elementos se componen, la experiencia de la revolución norteamericana permite verlos en conjunto: experiencia propiamente moderna de un encuentro entre virtud y fundación. La Revolución Americana es más que un hecho comprensible desde esa serie de condiciones históricas particulares (tal y como lo había sugerido en ¿Qué es la autoridad?): es un acontecimiento político. Sin dudas caeríamos en una simplificación si buscamos aquí la resolución de los problemas implicados en los anteriores abordajes, imaginando que tal "acontecimiento" resuelven los cuadros conceptual antes trazados - entre lo público y lo privado, lo moral y lo político, la 
cuestión social y la política, la necesidad y la libertad, la fundación, la violencia y la revolución -, sea desde o más allá de una teoría republicana.

Volvamos a recordar nuestra perspectiva de análisis. No buscamos abordar todas estas cuestiones, centrales para el pensamiento político arendtiano, adoptando a Maquiavelo como clave para su elucidación: consideramos que su lectura de Maquiavelo permite seguir un rastro que posibilita iluminar algunos motivos claves para interrogarnos sobre la relación entre Arendt y el republicanismo; una vía que se descubrirá en las muchas veces imperceptibles alteraciones de su interpretación, más que en el marco general de las aparentes continuidades que podrían estar dadas por la adopción de un maquiavelismo republicano. A tal fin, nos interesa identificar los motivos más significativos de su lectura en ciertos pasajes de esta obra:

1) Lo que hace de Maquiavelo una figura relevante para la historia de la revolución, de la cual fue precursor, es que fue el primero que meditó sobre la posibilidad de fundar un cuerpo político permanente, duradero y perdurable (...) [sin embargo], "lo que le distingue de los hombres de las revoluciones es que concebía su fundación (...) como una rinovazione, y la renovación constituía para él la única alterazione asalute (...) en otras palabras, el «pathos» específicamente revolucionario de lo absolutamente nuevo (...) le era totalmente extraño (Arendt, 1992, p.37).

Su proximidad con los revolucionarios del siglo XVIII se encuentra en el papel que juega la violencia en la tarea de la fundación, pero ya no compartirá de la misma manera con Robespierre la idea de crear una novedad absoluta. En Maquiavelo la central cuestión de la estabilidad y duración de la fundación no se plantea según las demandas de lo radicalmente nuevo.

2) “Consecuencia directa de la doble perplejidad", en la que, según Arendt, Maquiavelo se encontró teóricamente y los revolucionarios modernos prácticamente, "era inherente a la tarea de la fundación, al establecimiento de un nuevo origen que, en cuanto tal, parecía exigir la violencia y la usurpación (...) acompañada de la tarea de dar leyes, de proyectar e imponer a los hombres una nueva autoridad" (Arendt, 1992, pp.39-40, la cursiva es nuestra) ${ }^{12}$. Pero el desencuentro entre duración y novedad resulta de una sustitución que deviene restitución: el absoluto de la autoridad divina medieval. El Maquiavelo crítico de la religión, en el que Arendt ha insistido en cada una de sus menciones, es reconducido a sus límites, en la medida en que "se ve forzado a implorar la asistencia divina". Y si efectivamente, en la práctica, la

última etapa de la tarea revolucionaria, el hallazgo de un nuevo poder absoluto que remplace el absoluto del poder divino, carece de solución, debido a que el poder, dado el supuesto de la pluralidad humana, nunca puede aspirar a la omnipotencia, ya que las leyes que dependen del poder humano nunca pueden ser absolutas (idem,

12 En las dos únicas menciones de Maquiavelo en La vida del espíritu, Arendt lo presentará con motivo de la cuestión del aparecer y a la tarea de la fundación. Cf. Arendt, 2002, pp.153 y 445. 
p.40),

por su parte, el mismo Maquiavelo quedará atrapado en esta dificultad, puesto que

su insistencia en el papel que desempeña la violencia en la política no se debió tanto a su pretendida concepción realista de la naturaleza humana, como su vana esperanza de querer encontrar en ciertos hombres cualidades comparables a los atributos divinos (idem, ibidem).

El condotiero, que en anteriores lecturas expresaba la figura moderna de la antigua virtud, aquí quedará identificado con cualidades que pretenden infructuosamente sustituir el absoluto del poder divino.

3) Maquiavelo libera su fuerza teórica en la recuperación de las experiencias del pasado, de la virtud griega y la fundación romana, y aunque quedó atrapado en la idea medieval de autoridad, "fue mucho más allá que las experiencias reales de su época" (Arendt, 1992, pp.40-1), puesto que introdujo un nuevo vocablo en la teoría política, lo stato. Esta nueva entidad, distante de las antiguas ciudadesestado como de la sustitución del poder absoluto en la figura del condotiero, deviene un señalamiento que, por otra parte, no es directamente ligado a una figura de la fundación de lo nuevo. La novedad es histórica, Maquiavelo es el primer pesador del Estado, pero no sería propiamente una apertura política a lo nuevo.

4) Finalmente, si Maquiavelo va más allá de su época, es porque los tumultos, rebeliones y revueltas presentes en sus escritos "nunca significaron liberación en el sentido implícito en la revolución” (Arendt, 1992, p.41). Ni en la Grecia clásica, menos aun en Roma, y tampoco en el Renacimiento, las rebeliones populares "exigieron la igualdad de derechos", es decir, "la igualdad de los seres humanos en virtud de su nacimiento (...) como un derecho innato" (idem, ibidem). Para explicar esto, no sin ambigüedad, Arendt convoca nuevamente a la figura de los condotieri, ahora realzando su raíz clásica, señalando que la virtud se establece como principio de diferenciación frente al pueblo, producto del prestigio y no del origen social o el nacimiento (pero tampoco una diferencia absoluta según la lógica de la trascendencia, como señalamos en el punto 2). De manera tal que, aunque la historia está poblada de rebeliones, "no hubo ninguna que describiese un cambio tan radical como el de la transformación de los súbditos en gobernantes" (idem, p.42).

¿Esta lectura concluye en la exclusión de Maquiavelo como legado republicano para las revoluciones moderas? La insistencia de Arendt en señalar las distancias de Maquiavelo con el desafío moderno de la revolución entendemos que están ligadas a un intento por establecer los límites presentes en las primeras lecturas republicanas que centrarán su discurso en esa historia subterránea del humanismo cívico florentino como momento fundacional del republicanismo moderno. Arendt considerará tres dimensiones que enmarcan su lectura y que nos permiten suponer la insistencia en 
establecer esta distancia:

1) La primera podría considerarse de orden metodológico: no es en la historia de los conceptos sino en la comprensión del acontecimiento de la revolución lo que hace posible encontrar a Maquiavelo como el primer antecedente de las revoluciones modernas, por más que el término "revolución" no sea utilizado por él (cf. Arendt, 1992, p.36). La historia intelectual busca continuidades en el lenguaje político como justificación de una tradición, perdiendo de vista la comprensión de la singularidad de un momento, que se relaciona de manera no lineal con el pasado justamente porque se enfrenta a la cuestión de la fundación.

2) La segunda es de orden histórico: “desde el punto de vista político, el increíble desorden de las ciudades-estado de los siglos XV y XVI constituyó un final y no un origen; fue el fin de los municipios medievales con sus regímenes autónomos y su libertad de acción política" (Arendt, 1992, p.39). Aunque esto no explique cabalmente el silencio sobre el renacimiento italiano en la recuperación de la vita activa que reconstruye en La condición humana, sí permite entender por qué la tradición del humanismo cívico no puede ser la clave para comprender el núcleo de un republicanismo propiamente moderno, que asuma como centro de gravedad el problema de la fundación.

3) Y la tercera es de orden político, donde confluyen las dos observaciones anteriores:

Lo cierto es que, por inclinados que nos sintamos a interpretar nuestras propias experiencias a la luz de aquellas que proporcionaron las luchas civiles que arrasaron las ciudades-estado italianas, estas no fueron tan radicales como para sugerir a quienes participaban en ellas o fueron sus testigos la necesidad de un nuevo vocablo o la reinterpretación de uno antiguo (Arendt, 1992, p.41).

Porque el único vocablo nuevo formulado por Maquiavelo nada tiene que ver con las experiencias de las ciudades-estado, justamente porque se trata de lo stato.

La comprensión de la revolución como acontecimiento moderno no permite una interpretación ligada a la recuperación de las “tradiciones” clásicas. El Maquiavelo de Arendt no es el florentino amante de los clásicos ni el restaurador de la virtud: como dirá al final de ¿Qué es la autoridad? -parafraseando al Marx de El 18 Brumario -, tanto Maquiavelo como Robespierre se vistieron con ropajes romanos. Su verdadera novedad es haber formulado por primera vez la necesidad de innovar, y lo que parece un juego de palabras encuentra su término: Estado, diferente a la fundamentación jusnaturalistas y juscontractualista de la soberanía que se encuentran a la base de las revoluciones moderas. La relación entre violencia y fundación, que es su otra novedad, no tiene al Estado como sujeto, pues en Maquiavelo no es el Estado el absoluto que - como quiso la influyente interpretación de Hegel - podría garantizar la sustitución de la autoridad del poder divino. 
En su lectura de Sobre la revolución, la más completa y sistemática, Arendt devuelve a Maquiavelo al lugar de un umbral histórico, que interrumpe el continuo de una tradición, pero también difiere de esa experiencia asociada a la idea de acontecimiento, una experiencia comprehensiva y práctica de un tiempo que se abre a la novedad. La persistencia de motivos maquiavelianos, compartidos por otros lectores de su tiempo - como la prioridad del espacio público, la virtud pública, el bien común no moral, la libertad política, la felicidad pública, entre otros - no es, entonces, lo más relevante de su singular interpretación. Es otro aspecto sobre el que esta compleja y a veces ambigua lectura insistirá: la contingencia históricopolítica, que es su verdadera novedad y es lo que, al mismo tiempo, permite marcar las distancias entre su pensamiento y la revolución moderna. Maquiavelo le permite exponer la tensión entre tradición y novedad, arrastrada indefectiblemente por el neo-republicanismo, que sosteniendo el principio histórico-político de la "tradición", piensan el presente a la luz de las continuidades. Maquiavelo es el operador histórico-conceptual que permanentemente señala los límites de aquellas vías de fundamentación de una "tradición republicana", sea neo-aristotélica o neomaquiaveliana, pero también, más allá de su función polémica, aquel en donde son reconocibles los desplazamientos que tensionan los signos de la política moderna, nudos que exponen las propias perplejidades contenidas en Sobre la revolución. Para decirlo de otra manera, Maquiavelo es a la vez el lente y el espejo en donde emergen las tensiones entre republicanismo y revolución, en la fundamental cuestión de la fundación de lo político. Motivo por el cual, por otra parte, este problema no será ajeno al propio análisis de Arendt sobre la Revolución Americana y sus actores. Es aquí donde el vínculo entre Arendt y Maquiavelo se hace más estrecho; no, claro está, por la identidad de una doctrina política o de las repuestas que da, que Arendt somete a crítica, sino por la conciencia del problema que representa ese nudo esencialmente político entre pasado y futuro.

\section{Republicanismo y fundación}

¿Arendt lee de manera correcta a Maquiavelo? Son muchos nuestros diferendos sobre la lectura que nos propone de Maquiavelo (cf. Torres, 2012), reconocemos que algunos de ellos encuentran un motivo en la ausencia de una "interpretación" sistemática, algo que, como hemos podido ver hasta aquí, no era un objetivo de Arendt: como lo anunciamos, carece de sentido juzgar su lectura en tales términos, de lo que se trata es de interrogarnos por la función de Maquiavelo en su obra, los efectos que producen y los problemas que abre. Hasta aquí hemos intentado mostrar cómo opera Maquiavelo en su obra; en cuanto a los problemas que abre, el espectro es más amplio que los límites que hemos impuesto a este trabajo. Por ello, y a 
modo de conclusión, nos proponemos avanzar parcialmente sólo sobre un aspecto que entendemos ilumina parte del nudo de Sobre la revolución, ligado a la trama desarrollada a partir de las ideas de necesidad y fundación.

Para comenzar, conviene llamar la atención sobre un aspecto que muchas de las actuales lecturas influenciadas por el maquiavelismo contemporáneo pasan por alto: Arendt no propone una lectura conflictivista de Maquiavelo. Lo central de su pensamiento no se encuentra en su fuerza agonista (cf. Abensour, 1998); por el contrario, en Sobre la revolución resalta su voluntad de "fundar un cuerpo político permanente, duradero y perdurable" (Arendt, 1992, p.37). Esto no permite por sí mismo y en consecuencia inscribir al pensamiento de Arendt en un modelo consensualista (como lo proponen Mouffe (1999) y Marchart (2009), oponiéndola al modelo schmittiano del conflicto). Lo que está en juego en su lectura no es la dicotomía conflicto-consenso (que, por supuesto, no es equiparable a aquella entre poder y violencia), sino antes bien la problemática tensión - que en ocasiones Arendt considera irresoluble - entre novedad y duración, propia de toda fundación revolucionaria; es en ella donde Maquiavelo instala para la modernidad la contingencia de lo político y, por extensión, también una forma de comprender la necesidad, por fuera de una determinación nopolítica de la política (léase, una necesidad metafísica o natural). Esta cuestión está en el corazón de Sobre la revolución y permite cuestionar por lo menos dos conocidas lecturas que tienden a reducir la obra a estos núcleos: la ontologización de la escisión entre la cuestión social y la fundación política (la oposición necesidad-libertad), y la absolutización del consejismo jeffersoniano y tocquevilleano como paradigma de la acción, apuesta a las instituciones intermedias de la sociedad civil que abandona el problema de la institución del Estado (la oposición acción-institución).

En La condición humana la génesis de la distinción entre esfera privada y esfera pública, y su borramiento a partir de la emergencia de la cuestión social, es apoyada sobre la distinción entre labor, trabajo y acción. En Sobre la revolución la cuestión reaparecerá a partir del igualitarismo del derecho natural moderno, verdadera novedad que, sin embargo, retrasaría la misma idea de la fundación de un nuevo orden, tragedia de la revolución francesa. De esta génesis conocemos su corolario más nombrado: la identificación entre necesidad natural y cuestión social, frente a la absoluta autonomía de la identidad entre libertad y política. Como vimos, en La condición humana Maquiavelo es inicialmente aproximado al aristotelismo, aunque encontrará en una evidente distancia, que Arendt no relevará en ese momento: la idea de una "necesidad política" propiamente moderna, que en términos maquiavelianos no es ni contraria ni incompatible con la contingencia y la libertad, sino resultante de ellas. Se trata justamente de la necesidad de la fundación de una nueva institución, que llamó lo stato, cuyas acciones - en la medida en que su fundamentación natural y teológica ha sido impugnada - no podrá fundarse tampoco en la experiencia secular 
de la ciudad-estado clásicas o renacentistas, tal y como lo reconoce Arendt.

En los papers de su curso de teoría política dictado en 1955 y replicado con modificaciones en 1965, Arendt dedica unas páginas a Maquiavelo. Las notas recorren varios motivos que reaparecerán posteriormente y que, como vimos, van acumulándose en esa lectura de conjunto: la crítica a la religión, la recuperación de la virtud, los condotieri como nuevos fundadores, la bondad y la gloria. Pero aquí despliega brevemente un análisis sobre la novedad del Estado, que en los textos que hemos trabajado siempre es mencionada pero nunca tratada:

La acción de ese hombre nuevo [el condotiero], funda una nueva organización, un cuerpo político, debe seguir ciertas normas que son igualmente «nuevas»: una nueva moralidad, pero no una razón de Estado. No es el Estado, una institución, la que razona, son los hombres. Es la necesidad, y no la razón, la que «obliga» a los Estados a «numerosas cosas a las cuales la razón no los empuja» $(\mathrm{D}, \mathrm{I}, 6)$. Para la razón no es la necesidad y la necesidad no es lo razonable. Si la necesidad está de su parte, puede imponer la razón a la no-razón. Que dicha necesidad pueda ser, por ella misma, quizás, razonable, racional, es una idea extraña a Maquiavelo" (...) “Maquiavelo tenía razón: el Estado-nación podía desarrollarse bajo la forma de una monarquía absoluta y de una república. Maquiavelo contempla las dos, no desde el punto de vista de un desarrollo histórico, sino como igualmente posibles (Arendt, 2002a, p.39) ${ }^{13}$.

Podríamos imaginar que Arendt realiza una crítica a esta nueva forma de necesidad estatal que surge en la modernidad, y sin duda en parte es así. Pero en este críptico juego conceptual también dice otra cosa. Esta necesidad nada tiene que ver con la necesidad natural (para Maquiavelo la necesidad natural biológica o social no es relevante, no se trata de ningún modelo organicista de Estado ${ }^{14}$ ), tampoco de una necesidad racional trascendental o teleológica (no hay una filosofía de la historia, como en Kant o Hegel), ni, por supuesto, una necesidad funcionalista, como en las teorías de la "razón de estado": la necesidad no se liga a la fundamentación pre-política, sea empírica o trascendental, sino a la fundación política. Así, lo propio de la fundación moderna, su novedad y problema es la no necesaria coincidencia entre lo razonable para los hombres y lo razonable para la institución política, es la contingencia de la necesaria relación entre acción e institución. Es por ello que entre lo necesario y lo razonable el Estado posee esa doble valencia que Maquiavelo supo reconocer: hacer de esa necesidad violencia, e imponerla sobre lo razonable, o hacer de esa necesidad virtud, una novedosa forma de la libertad política, una libertad que no puede existir sino como parte constitutiva de la fundación moderna

13 Fragmento del manuscrito traducido como "Una bitácora para leer a Maquiavelo" (Arendt, 2002a); publicado originalmente en francés Magazine littéraire, 397, abril de 2001, tomado del manuscrito en inglés propiedad de Hannah Arendt Literary Trust.

14 "Maquiavelo menciona una vez la necesidad de los hombres de defenderse y este es probablemente el primer motivo que tienen los hombres para reagruparse dentro de cuerpos políticos. Pero esto no le interesa. La política en sí misma no tiene fin, ésta no es un medio" (Arendt, 2002a, p.42) La referencia de Arendt es al cap. 1 del primer libro de los Discursos. 
de la institución política (por eso - como reconoce Arendt - para Maquiavelo el Estado podía ser monárquico o republicano).

Resalta entonces una diferencia entre la lectura de Maquiavelo y de Robespierre que Arendt sugerirá, sin insistir en ella: el problema de la violencia no se vincula necesariamente a la cuestión social - aunque pueda ligarse y no exclusivamente, en términos históricos -, ni se resuelve en la contraposición clásica entre monarquíarepública. Es decir, el problema no está directamente asociado a la subsunción aristotélica de la necesidad a la libertad, ni a la subsunción jacobina de la libertad a la necesidad y, por tanto, ya no es la distinción clásica entre república y monarquía la que resuelve la indistinción moderna entre libertad y dominio. Pero más relevante aún es que la cuestión de la libertad política moderna no puede ser decodificable en los términos clásicos de la isonomía, porque requiere de la institución del Estado, de una nueva ley secular, para que se haga posible. Si bien en La condición humana Arendt no identificará la condición política a las condiciones históricas, es cierto también que la "ontología" política es pensada a partir de categorías ligadas a la experiencia de la polis, donde no encontramos el problema de la institución de la política (que nada tiene que ver con las instituciones en términos de formas de gobierno, según las conocemos a partir de la casuística clásica, aunque sí sigue vigente para la distinción tiranía-república). Así, por una parte encontramos una reflexión sobre la acción (sobre la vita activa) en el marco de una relación entre libertad y necesidad, mientras que por otra parte esa misma relación no da cuenta plenamente del problema moderno de la institución (sino bajo la forma malograda del Estado soberano), que debe pensar simultáneamente la acción y las condiciones de la acción.

Como propone Arendt, la Revolución francesa es un acontecimiento marcado por el encuentro entre libertad y necesidad, que toman consistencia en una problemática teoría de la soberanía; la Revolución americana, que por motivos contextuales no se enfrentó directamente a la cuestión social, no por ello quedó exenta de tener que dar cuenta de esa otra necesidad, la de fundar un orden nuevo, un nuevo Estado, donde se presentarán problemas de igual magnitud, aunque no idénticos. La cuestión del Estado, que Arendt insistirá aparece con Maquiavelo, no se resuelve en la contraposición entre un modelo soberanista que neutraliza la participación pública, y un modelo comunalista que sortear el problema con la creación de un espacio no estatal, las asociaciones civiles que fomentan la participación pero mantienen una relación externa, no directamente vinculante, frente al del Estado, reducido éste a garantizar las libertades en sentido negativo (el federalismo es uno de los nombres que condensan la dimensión del problema, en la medida en que supone una forma de gobierno que es vinculante para una forma de Estado, pero no su respuesta).

La distancia de Arendt frente al neoaristotelismo y el neorepublicanismo, 
muestra que ambas "tradiciones" asumen la novedad moderna en términos de una traducción histórica, cuya estructura podría enmarcarse en la distinción Sociedad civil-Estado: distinción normativa entre acción e institución, entre libertad y ley, sin considerar ese momento de la fundación en donde la cuestión de la constitución pone en juego, en un mismo movimiento, una acción cuya libertad debe ser necesariamente instituyente, creadora de nuevas formas institucionales de producción política, de un Estado no considerado negativamente, reducido a la salvaguarda de las libertades. Sería apresurado afirmar que esta cuestión que planteamos es la línea vertebral de Sobre la revolución, pero el problema está presente y nos indica por lo menos una vía de exploración donde la cuestión maquiaveliana es continuada bajo otro nombre, el de Montesquieu, que instala la relación inmanente entre ley y poder, y por extensión una idea de norma que es condición de posibilidad y expresión de las relaciones políticas, alcanzando a la institución del Estado y no sólo a la dinámica isonómica de los consejos (por lo que la cuestión de la relación entre acción y ley no puede ser reducida al paradigma de la "desobediencia civil", cuestión planteada frente al Estado existente, tan como aparece en Crisis de la república (Arendt, 2015. Cf. Cohen, y Arato, 2000; Balibar, 2007)).

Como hemos ido referenciando en varias notas, la presencia de Maquiavelo en otras obras y textos mantiene ciertos locus recurrentes. La relación ArendtMaquiavelo, por tanto, no tiene que ver con una interpretación sistemática integrada al corpus general de su obra sino, como creemos y hemos intentado mostrar, con un "momento maquiaveliano" que es el signo de su vínculo problemático con el republicanismo, pero también la vía para interrogarnos sobre las bases a partir de las cuales Arendt pensaría un republicanismo moderno, que asuma una relación lúcida con la tradición, pero que se piense a partir de la novedad modera de la revolución.

\section{Referencias}

Abensour, M. (1998). La democracia contra el Estado. Buenos Aires: Colihue. Arendt, H. (1992). Sobre la revolución. Buenos Aires: Alianza.

- (1997). ¿Qué es la política?. Barcelona: Paidós.

. (1998). La condición humana. Barcelona: Paidós.

- (2002). La vida del espíritu. Buenos Aires: Paidós.

núm. 23 , pp.38-42.

(2002a). Una bitácora para leer a Maquiavelo. Metapolítica, Vol. 6, Península.

. (2003). “¿Qué es la autoridad?”. In: Entre pasado y futuro. Barcelona:

Paidós.

(2003a). Conferencias sobre la filosofía política de Kant. Buenos Aires:

- (2007). Responsabilidad y juicio. Barcelona: Paidós.

- (2015). Crisis de la República. Madrid: Trotta. 
Balibar, E. (2007). La impolítica de los derechos humanos. Arendt: el derecho a tener derechos y la desobediencia cívica. Erytheis, 2, pp.84-114.

Barbuto, G. M. (2005). Machiavelli e i totalitarismi. Napoli: Guida Editore.

Baron, H. (1928). Leonardo Bruni Aretino. Humanistisch-philosophische Schriftten. Leipzig: Teubner.

. (1955). The Crisis of the Early Italian Renaissance: civic humanism and republican liberty in an age of classicism and tyranny. Princeton: Princeton University Press.

Cassirer, E. (1993). El mito del Estado. México: Fondo de Cultura Económica.

Cohen, J.L. y Arato, A. (2000). Sociedad civil y teoría política. México: Fondo de Cultura Económica.

Forti, S. (2001). Vida del espíritu y tiempo de la polis. Hannah Arendt entre filosofía y política. Madrid: Cátedra.

Gilbert, F. (1965). Machiavelli and Guicciardini: Politics and History in SixteenthCentury Florence. Princeton: Princeton University Press.

Habermas, J. (1987). Teoría y praxis. Estudios de filosofía social. Madrid: Técnos.

Marchart, O. (2009). El pensamiento político postfundacional. Buenos Aires: Fondo de Cultura Económica.

Meinecke, F. (1959). La idea de razón de Estado en la historia moderna. Madrid: Instituto de Estudios político.

Mouffe, C. (1999). El retorno de lo político. Barcelona: Paidos.

Pocock, J. G. A. (2002). El momento maquiavélico. El pensamiento político florentino y la tradición republicana atlántica. Madrid: Técnos.

Riedel, M. (1976). Metafísica y metapolítica: estudios sobre Aristóteles y el lenguaje político de la filosofía moderna. Buenos Aires: Alfa.

Ritter, G. (1940). Machstaat und Utopie: vom Streit um die Dämonie der Macht seit Machiavelli und Morus. Berlin: Oldenbourg.

(1976). "Maquiavelo y los orígenes del nacionalismo moderno". In: El problema ético del poder. Madrid: Revista de Occidente.

Skinner, Q. (2004). La libertad antes del liberalismo. México: Taurus.

Souroujon, G. (2011). Arendt y las lecturas republicanas de la revolución norteamericana. Fragmentos de filosofía, 9, pp.13-30.

Sternberger, D. (1992). “Maquiavelo, maquiavelismo y política”. In: Dominación y acuerdo. Barcelona: Gedisa.

Torres, S. (2012). Vida y tiempo de la república. Contingencia y conflicto político en Maquiavelo. Los Polvorines: Editorial de la UNGS.

Volpi, F. (1988). "Che cosa significa neoaristotelismo? La riabilitazione della filosofia pratica e il suo senso nella crisi della modernità". In: E. Berti (ed.). Tradizione attualità de la filosofia pratica. Genova: Marietti.

(1999). Rehabilitación de la filosofía práctica y neo-aristotelismo. Anuario filosófico, 32(63), pp.315-342.

Recebido em: 22.10.2015

Aceito em: 28.07.2016 